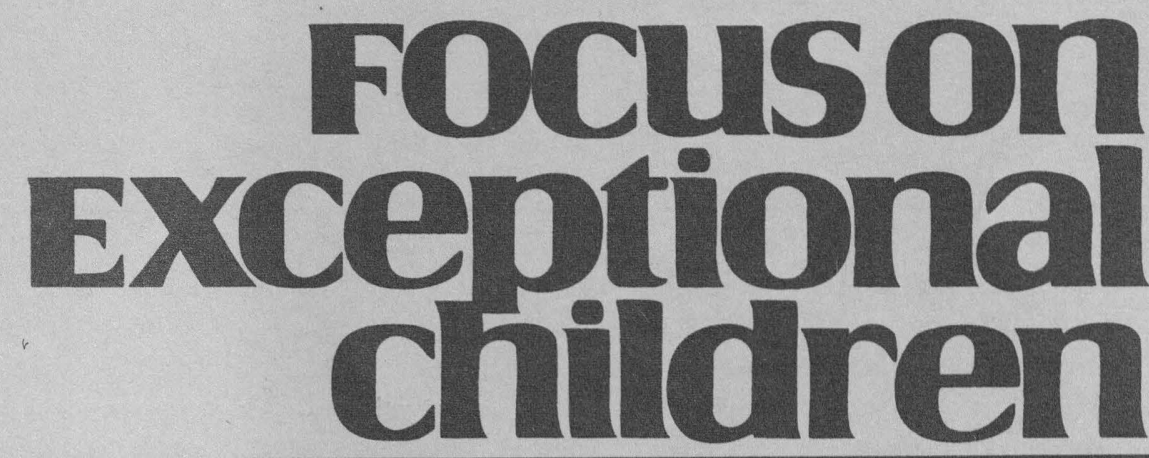

\title{
Crossing Boundaries: What Constructivists Can Teach Intensive-Explicit Instructors and Vice Versa
}

\author{
Jim Knight
}

\begin{abstract}
The next ten years will require people to think and work across boundaries into new zones that are totally different from their areas of expertise. They will not only have to cross these boundaries, but they will also have to identify opportunities and make connections between them. (Mok, 2003)

The one language we all share is a child's smile. It has the power to cross all boundaries.Dr. William Magee, Jr., \& Kathleen Magee, Operation Smile
\end{abstract}

Alex's parents had a lot of questions. Just recently, they had been asked to attend an IEP meeting at Alex's elementary school, and they were told that their thirdgrader was below an appropriate achievement level for his grade. Alex was a bright kid, everyone agreed, but he didn't seem to learn as effectively as others. The team at the school suggested that Alex be tested, and the subsequent assessment determined that Alex had a learning disability. Even though Alex's intelligence was above average, the educational professionals agreed that he would require special help to reach his potential in life.

Like many other children that Christmas, Alex received a sophisticated video game as a gift. He soon was plugged in and playing happily. Over the next few days, Alex played his game for hours each day, and he kept getting better at it. Four days after Christmas, Alex's older cousins, who were in high school, came to visit. They had received the same game for Christmas, but they had not yet learned nearly as much about it as Alex had. For two hours, Alex proceeded to tutor his older cousins in how to play the game, "Jump up and down here," he said, "and you'll find some coins." "Go through that door, and you'll turn invisible." The high schoolers were impressed-Alex had learned the entire language of the game in only 4 days, and he was only in third grade.

"How is it," Alex's parents asked, "that our son has learned so much about this game, and yet he's 'learning disabled' in school?" "Why does he love learning the game and hate learning in school?" "Are his teachers really seeing how smart he is?" "Are they building on his strengths?" "Are they teaching him in ways that will be best for him?" "Does he really have a learning disability?" 
The questions that Alex's parents asked are precisely the questions that educational researchers ask. No doubt many researchers would add other, general questions: "What are the most motivating instructional methods?" "How can teachers enable students to 'internalize' or 'generalize' knowledge?" "What is the teacher's role?" "What should students do?" "How does learning occur?" These general questions, fleshed out in hundreds of more specific research questions, constitute much of the academic conversation on instruction for students with disabilities.

This article provides some notes for understanding aspects of this academic conversation. Specifically, I consider one central conversation: the sometimes opposing thoughts and statements of researchers and theorists embracing either a constructivist or an intensive-explicit (IE) approach to instruction. I chose as a topic this professional debate, though controversial and unsettling for some, because it is multiparadigmatic and therefore holds the potential to be fruitful. We can learn a lot when we listen to someone who views our world from the outside (Bernstein, 1991).

\section{FOCuson Exceptional children}

ISSN $0015-511 \mathrm{X}$ FOCUS ON EXCEPTIONAL CHILDREN (USPS 203-360) is published monthly except June, July, and August as a service to teachers, special educators, curriculum specialists, administrators, and those concerned with the special education of exceptional children. This publication is annotated and indexed by the ERIC Clearinghouse on Handicapped and Gifted children for publication in the monthly Current Index to Journals in Education (CIJE) and the quarterly index, Exceptional Children Education Resources (ECER). The full text of Focus on Exceptional Children is also available in the electronic versions of the Education Index. It is also available in microfilm from Xerox University Microfilms, Ann Arbor, MI. Subscription rates: Individual, \$36 per year; institutions, $\$ 48$ per year. Copyright (C) 2002, Love Publishing Company. All rights reserved. Reproduction in whole or part withou written permission is prohibited. Printed in the United States of America. Periodical postage is paid at Denver, Colorado. POSTMASTER: Send address changes to:

$$
\begin{gathered}
\text { Love Publishing Company } \\
\text { Executive and Editorial Office } \\
\text { P.O. Box } 22353 \\
\text { Denver, Colorado } 80222 \\
\text { Telephone (303) } 221-7333
\end{gathered}
$$

$\begin{array}{cc}\text { Karen Harris } & \text { Thomas Skrtic } \\ \text { University of Maryland } & \text { University of Kansas }\end{array}$

James Shriner

University of Illinois

Erica J. Lawrence Editor
Stanley F. Love Publisher
To consider how intensive-explicit and constructivist instruction can impact instruction for students with disabilities, this article: (a) reviews the constructivist and intensive-explicit approaches to instruction, (b) identifies points of contrast between the two approaches, and (c) identifies points of convergence between the two approaches. By seeing the world from within both paradigms, perhaps we may uncover new and useful ways of seeing instruction regardless of our paradigmatic orientation.

\section{WHERE DID THE TERMS "CONSTRUCTIVIST" AND "INTENSIVE-EXPLICIT" COME FROM?}

I have chosen to use the terms constructivist and intensive-explicit. Unfortunately, I cannot give precise, limited definitions of these terms because they are used so differently by so many in the literature. I will consider the terms in the manner proposed by Schwandt (who references Blumer, 1954):
As general descriptors for a loosely coupled family of methodological and philosophical persuasions, these terms . steer the interested reader in the general direction [and] merely suggest "directions along which to look" rather than "provide descriptions of what to see. (Schwandt, 1994, p. 221)

The terms constructivist and intensive-explicit refer to many different pedagogies, some of which are complementary, some of which are mutually exclusive. The term constructivist has been used liberally in the education literature to refer to an ontology, epistemology, pedagogy, and critical perspective and has been linked with such concepts as radical constructivism (Glasersfeld, 1995), social constructivism and psychological constructivism (Phillips, 2000). I use the term intensive-explicit instruction to stand for an amalgam of individually unique approaches that have been described variously as strategic (Ellis, Deshler, Lenz, Schumaker, \& Clark, 1991), direct explanation (Roehler \& Duffy, 1984), and cognitive (Meichebaum, 1977) instruction.

The difficulty in pinning down these definitions is further complicated as many researchers and authors (Englert et al., 1995; Harris \& Graham, 1996; Pressley, Harris, \& Marks, 1992) support practices that share attributes of intensive-explicit and constructivist approaches. Before proceeding to the heart of this discussion, I will provide descriptions of both terms.

\section{WHAT IS CONSTRUCTIVIST INSTRUCTION?}

A central theme in the literature on constructivist instruction is the suggestion that "each of us makes sense of the world by synthesizing new experiences into what we have 
previously come to understand" (Brooks \& Brooks, 1993). Many constructivists contend that this deceptively straightforward idea has radical implications for how we live, think, learn, and teach, and even calls into question our notions of truth and reality. To understand constructivist instruction, then, we need to understand it as an approach that involves its own ontology, epistemology, and pedagogy.

\section{Constructivist Ontology}

If each of us constructs our own unique understanding of the world, it follows that each of us experiences (or constructs) our own unique world: Everyone's reality is different. As Glasersfeld (1995) has observed, radical constructivism

\footnotetext{
starts from the assumption that knowledge, no matter how it be defined, is in the heads of persons, and that the thinking subject has no alternative but to construct what he or she knows on the basis of his or her own experience. What we make of the world constitutes the only world we live in. It can be sorted into many kinds, such as things, self, others, and so on. But all kinds of experience are essentially subjective, and though I may find reasons that my experience may not be unlike yours, I have no way of knowing that it is the same. (p. 1)
}

Constructivists extend this discussion by agreeing with Kuhn's (1970) assertion that scientific knowledge can be understood as true only within a given paradigm and not in reference to an immutable standard in objective reality. Our notions of truth and objectivity, therefore, are open to question.

Furthermore, because some socially constructed terms limit, stereotype, or oppress individuals (especially women, people with disabilities, people in poverty, and racial minorities), issues of gender and power take on special significance. Words can tell us who we are, and because words are created by humans, thinking people should reflect on whether the words they live by are authentic for them and others (Reid, Robinson, \& Bunsen, 1995).

\section{Constructivist Epistemology}

Constructivist epistemology is the view that learning occurs because each of us uniquely creates or builds our own knowledge. In essence, we construct knowledge based on what we already know, and each idea we learn facilitates our ongoing intellectual development. Phillips (2000) summarizes this view as follows.

[The] constructivist view is that learners actively construct their own ("internal" some would say) sets of meanings or understandings; knowledge is not a mere copy of the external world, nor is knowledge acquired by passive absorption or by simple transference from one person (a teacher) to another (a learner or knower). In sum, knowledge is made, not acquired. (p. 7)
Constructivist theory is derived in great measure from Piaget (Piaget, 1954; Poplin, 1988a), who suggested that we construct new knowledge when we experience new information that is incongruent with our prior knowledge. Learning and development take place when we try to reconcile new knowledge with what we already know. A central concept for Piaget is the process of assimilation:

No behavior, even if it is new to the individual, constitutes an absolute beginning. It is always grafted onto previous schemes and therefore amounts to assimilating new elements to already constructed structures (innate, as reflexes are, or previously acquired). (Glasersfeld, 1995, p. 62)

Piaget's theory was extended by Vygotsky's "zone of proximal development," in which intelligence is seen as dynamic rather than fixed. For Vygotsky, the construction of knowledge is a process: "Learning and development do not coincide" (Vygotsky, 1978, p. 84). The zone of proximal development can be understood as the gap between a person's current intellectual level and a person's potential level. That is, the zone defines "those functions that have not yet matured but are in the process of maturing" (p. 86).

Thus, the zone is "the distance between the actual developmental level as determined by independent problem solving and the level of potential development as determined through problem solving under adult guidance or in collaboration with more capable peers" (p. 86). Vygotsky also suggests that each child's development within his or her zone of proximal development is enabled through frequent, social interaction.

\section{Constructivist Pedagogy}

Constructivist pedagogy is more general than specific, thereby allowing teachers the freedom to construct their own individual pedagogy based on constructivist principles. Nevertheless, Brooks and Brooks (1993) offer a list of constructivist traits, suggesting that constructivist teachers

(a) encourage and accept student autonomy and initiative (p. 103);

(b) use cognitive terminology ... when framing tasks (p. 104);

(c) allow student responses to drive lessons, shift instructional strategies and alter content (p. 105);

(d) inquire about students' understandings of concepts before sharing their own understanding of those concepts (p. 107);

(e) encourage students to engage in dialogue (p. 108);

(f) provide time for students to construct relationships and create metaphors (p. 115); and

(g) nurture students' natural curiosity through frequent use of the learning cycle model. (p. 116)

Vygotsky's work is especially influential in the literature on constructivist instruction for students with disabilities (Englert et al., 1995; Mariage, 2000). Belief in the zone of 
proximal development repositions the teacher as a facilitator (rather than an expert), and thus a teacher strives to provide scaffolding (Wood, Bruner, \& Ross, 1976) that enables students to develop their full potential. In addition, the teacher facilitates discourse and dialogue within the classroom, which enables students to internalize learning that takes place in school (Mariage, 2000). Although Moshman (1982) has described constructivism as occurring along a continuum of service, depending on the extent of teacher direction, most teachers using constructivist pedagogy spend more time mediating conversations and learning opportunities than they do directly explaining content.

Constructivist instruction, then, is an educational approach that involves an interwoven pedagogy, epistemology, and ontology, all based on the central thesis that people learn by making their own sense of the world rather than by acquiring fixed knowledge that already exists.

\section{WHAT IS INTENSIVE-EXPLICIT INSTRUCTION?}

The loosely coupled group of instructional practices that I refer to as intensive-explicit instruction has no single ontology or epistemology, although intensive-explicit instruction is often characterized as empiricist (Heshusius, 1995). In truth, the border between intensive-explicit and constructivist instruction is less and less obvious because, increasingly, authors consider themselves constructivists and still propose an intensive-explicit instruction pedagogy (Harris \& Graham, 1999; Mercer, Jordan, \& Miller, 1996).

Intensive-explicit instruction, at least for the purposes of this article, refers to a set of instructional procedures that together efficiently and effectively enable teachers to convey content clearly to students in a manner that leads to students' mastering information. IE is intensive because it involves teaching practices that ensure that students are engaged in learning and actively mastering content (Ellis et al., 1991). IE is explicit because it involves teachers' clearly modeling covert thinking (Mercer, Lane, Jordan, Allsop, \& Eisele, 1996; Roehler \& Duffy, 1984) and providing detailed feedback as students move toward mastery of content (Kline, Schumaker, \& Deshler, 1991).

Although IE instruction can take place in many rich, meaningful contexts (Deshler et al., 2001; Graham, Harris, \& Larsen, 2001), a primary goal of intensive-explicit instruction is for students to understand, remember, and generalize content taught by a teacher. Simply put, instructors use intensive-explicit instruction so that students will have a picture of knowledge in their head that is similar to the picture teachers have in their head. Intensive-explicit instruction utilizes most of the following instructional stages to achieve this goal: describe, model, vocabulary memorization, practice and feedback, and generalization.

\section{Describe}

During the Describe stage of instruction, the teacher explains the content or procedural knowledge the students are going to master (Ellis et al., 1991; Harris \& Graham, 1999). For example, a teacher teaching students the Paraphrasing strategy (Schumaker, Denton, \& Deshler, 1984 Read a paragraph, ask yourself what the main idea and details are, put the main idea and details into your own words) would explain the strategy in detail during the Describe stage of instruction. The kind of discourse that takes place during this stage is highly interactive, much more interactive than some constructivists advise (Poplin, 1988b).

During the Describe stage, an IE teacher uses questioning techniques to maintain student engagement and to clarify whether students do or do not understand the material being presented.

IE teachers who employ the strategic instruction model (Ellis et al., 1991) - for example, follow a 3-to-1 rule; that is, they do not make more than three statements without having students respond in some way (for example, answering a question, turning to a neighboring student to paraphrase content, writing notes, responding to questions).

IE is designed to compensate for the learning difficulties many students have. Thus, content to be covered is enhanced to make it more easily understood through the used of acronyms, visual images, and graphic organizers (Deshler et al., 2001). In addition, IE provides explicit cues for note taking, and essential content is displayed visually, described verbally, and recorded physically by students.

\section{Model}

A central proposition with the IE paradigm is that people learn a great deal by watching what and how others do what they do (Bandura, 1971). Thus, once students have heard, seen, and recorded content, they benefit from explicit modeling of the thinking embedded in the content being learned (Ellis et al., 1991; Roehler \& Duffy, 1984).

For example, a teacher teaching the Paraphrasing strategy demonstrates how to use the strategy on a reading passage. Modeling is highly structured, beginning with an advance organizer in which the students and teacher review content that was explained during the Describe stage of instruction. Following this, teachers deliberately demonstrate the thinking they want students to learn. Thus, rather than simply "thinking aloud," teachers using IE are deliberate about clearly demonstrating the essential thinking they want students to learn (Gildroy, 2001).

Once students have seen a complete model, teachers involve them in the task at hand-in this example, using the Paraphrasing strategy. The teacher calls on students to help 
them complete the task, and the teachers and students discuss the kind of thinking patterns that will lead to effective use of the strategy. This stage concludes with a teacher-led review.

\section{Vocabulary Memorization}

During the stage of Vocabulary Memorization, the teacher leads the students through activities that enable them to memorize the critical components of the content being learned (Ellis et al., 1991). Students learning the Paraphrasing strategy, for example, memorize the steps of the strategy and the criteria for successful performance of the strategy.

Activities may include rapid-fire verbal rehearsal, in which the teacher calls on students to speak back key terms quickly; peer practice, in which two students question each other about the terms and definitions; games that involve groups of students in friendly competition; sustained, silent review, and so on. During this stage the teacher's goal is for students to understand and remember all the essential vocabulary.

\section{Practice and Feedback}

"The essence of strategy instruction," Borkowski comments, "lies in explanation followed by challenging and extensive practice" (Borkowski \& Muthukrishna, 1992). Consistent with this tenet, teachers using IE ensure that students master content by providing practice activities. These practice activities are organized so students develop their skills progressively; that is, they learn strategies, skills, and content by mastering increasingly difficult tasks. For example, a student learning Paraphrasing might start by paraphrasing words, then phrases, then whole sentences. Subsequently, the student might practice on short, easy-to-read materials before progressing to more difficult longer passages.

During the Practice and Feedback stage, the teacher provides extensive feedback to students on their progress, and students often chart their progress. Specifically, during each feedback session for Paraphrasing, the teacher (a) authentically praises each student for what he or she has done well, (b) notes a category of error in the students' work, (c) models for the student a way to avoid that error, (d) and ensures that the student understands what to do differently by asking the student to demonstrate how to perform the practice attempt correctly (Kline et al., 1991).

Feedback of this kind enables students to overcome learned helpless (Seligman, 1992) about major academic tasks by constantly demonstrating to students that they are developing. As students apply feedback in subsequent practice attempts, they become more and more skillful until they have mastered the content to be learned.

\section{Generalization}

A central goal of IE is that students' use of strategies, skills, or content becomes habitual in a variety of settings. As Deshler and Schumaker have observed about strategic instruction, "Over time, the focus of instruction should shift from teaching students to use a task-specific strategy to focus on how to meet the demands associated with a specific problem or to a focus on how strategies can be used to address similar problems in the same or other domains" (Deshler \& Schumaker, 1993, p. 163). For that reason, teachers using IE instruction explicitly guide students to generalize their use of the information being learned. The teachers describe, when, where and why students should use knowledge such as Strategies in a variety of settings, both in school and in their lives.

Teachers using IE instruction often have students turn in assignments in which they demonstrate use of strategies in settings outside of their classroom, provide feedback on students' attempts at generalization, and encourage other teachers to cue students to use strategies taught in their classes. For example, a teacher teaching the Paraphrasing strategy might discuss with students how paraphrasing could be used as a listening strategy during conversation, a note-taking strategy during lessons, a reading comprehension strategy while doing research or reading textbooks, and so on. In addition, the teacher might have students actively practice use of the strategy on a variety of academic and less formal reading materials.

Intensive-explicit instruction is an amalgam of teaching strategies used in concert to ensure that students master content. Students experiencing intensive-explicit instruction receive explicit, interactive explanations of content, watch teachers model thinking, memorize key vocabulary, practice and receive feedback until they master content, and ultimately receive explicit instruction, prompts, and feedback to help them generalize their learning to other settings inside and outside school.

\section{POINTS OF CONTRAST}

One way to better understand the intensive-explicit and the constructivist approaches to instruction is to look at how they differ with respect to specific aspects of practice in the classroom and in schools. Each approach includes many practices that may be contrasted. For example, both approaches see the teacher's goal as enabling students to become independent, self-regulated learners (Deshler \& Schumaker, 1988; Reid et al., 1995), and both approaches propose that teachers need to provide "scaffolds" to accommodate students' lack of prerequisite knowledge (Ellis et al., 1991; Mariage, 2000; Pressley, Hogan, Wharton-McDonald, 
Mistretta, \& Ettenberger, 1996). However, the way teachers go about enabling self-regulation or providing scaffolds differs greatly between the two approaches.

The intent here is not to contrast specific constructivist and intensive-explicit teaching practice (though that certainly would be a profitable, if complicated, task). Rather, the focus will be on contrasting components of educational practice in the classroom: (a) the teacher's role, (b) conversations, (c) questions, (d) errors, (e) activities, (f) motivation, and $(\mathrm{g})$ truth and reality.

\section{Teacher's Role}

\section{Intensive-Explicit}

The primary goal of teachers using the IE instruction approach is to teach so effectively that every student masters and generalizes the content being covered. The IE teacher uses teaching practices that accommodate students' learning challenges; the teachers are explicit about thinking processes, feedback, generalization, and so on because they want students to learn and generalize content in pretty much the same form as it is presented.

IE teachers alternate between assessing students and providing instruction (sometimes almost simultaneously). They assess whether students are comprehending instruction, or mastering application of knowledge, while teaching utilizing content enhancements that render content more accessible to students (Deshler, Schumaker, Bulgren et al., 2001; Deshler, Schumaker, Lenz et al., 2001).

\section{Constructivist}

Skrtic, Sailor, and Gee (1996) comment that, "In constructivist classrooms, teachers are viewed as agents who encourage students to be thinkers and who involve students in the whole problem-solving enterprise" (p. 147). A constructivist teacher plays a less central role in the classroom than does an IE teacher, but his or her challenge is no less complex.

A constructivist teacher is interested primarily in enabling all students to construct and internalize their own unique knowledge. Toward that end, constructivist teachers are mediators; they mediate the community of the classroom so the dialogue enables students to develop intellectually, and the teachers put in place scaffolds that enable students to develop within their zone of proximal development (Moll, 1990). Poplin's (1988b) comments clearly illustrate this new understanding of the teacher's role: "The more control educators have over the content, the less likely students will be to maintain and generalize skills and/or strategies."

\section{Conversations}

\section{Intensive-Explicit}

When using IE instruction, the teacher structures the conversation to ensure that students master content, although a good deal of conversation is interactive. During IE instruction, conversation serves two purposes:

1. The teacher explicitly explains the thinking embedded in the strategies, skills, or content (Pressley et al., 1990; Roehler \& Duffy, 1984).

2. The teacher guides students to write appropriate information during notetaking, models thinking processes, and so on.

IE instruction is not a lecture, however. Teachers using IE use their entire repertoire of teaching skills to ensure that students are engaged and understand whatever is being discussed (Harris \& Graham, 1999). Once students have mastered content, the teacher shifts the conversation to discuss how students can use what they have learned in a variety of settings in school and real life. Strategy mastery serves "as a good point of departure for stimulating dialogue between the teacher and student about 'learning how to learn"' (Deshler \& Schumaker, 1993, p. 155).

A flowchart depicting the direction of conversation in an IE classroom would show conversation taking place between students (when they practice learning in teams or groups) and from students to teachers (when students ask for clarification of content, or when they extend the conversation based on teacher prompts). Nevertheless, the majority of conversations during IE instruction start with the teacher and end with the student.

\section{Constructivist}

Dialogue is the mode of discourse in constructivist classrooms. Dialogue is seen as a way for students to share their knowledge and thereby facilitate each other's construction of knowledge (Vygotsky, 1978). Bohm (1996) sheds light on the meaning of dialogue by uncovering the etymology of the term:

\footnotetext{
Dialogue comes from the Greek word dialogos. Logos means "the word" or in our case we would think of the "meaning" of the word. And dia means 'through'... A dialogue can be among any number of people ... the picture or image that this derivation suggests is of a streaming of meaning flowing among and through us and between. (p. 6)
}

For constructivists, dialogue is a necessary means to develop further thinking. In this sense, the contructivist understanding of dialogue is Frierean (Friere, 1997). That is, by providing us with a variety of perspectives on ideas, dialogue creates the freedom for us to re-create knowledge. For 
Friere, reflection that occurs through dialogue - the opportunity to recreate our own knowledge-is an essentially humanizing activity. Poplin (1995) builds upon other aspects of Friere's "revolutionary pedagogy" by suggesting that authentic education should empower students to reflect on and transcend their situation in the world.

By contrast to intensive-explicit instruction, a flowchart of the direction of conversation in a constructivist classroom would look quite chaotic, with multiple conversations between students working on authentic tasks, and between students and teachers. Unlike intensive-explicit instruction, more conversations would start with students and end with the teacher, or start with students and end with other students.

\section{Questions}

\section{Intensive-Explicit}

Teachers using IE pose questions primarily to gauge whether students understand or are mastering content. In addition, teachers pose question to help students clarify their own understandings and misunderstandings. Students ask questions when they are unclear about the content or the components of an assignment. This is not to say that IE teachers refrain from offering provocative, challenging questions. This sort of questioning is a characteristic of most exciting learning situations. During IE instruction, however, questions help the student and the teacher better understand whether a student has acquired the knowledge being taught. Also, because questions are used to assess student comprehension and development, they usually have right and wrong answers.

\section{Constructivist}

In constructivist classrooms questions are posed to inspire authentic problem solving. That is, questions bring to the surface incongruities that students have to address, and students frequently work in groups to construct new knowledge. Questions help students develop higher forms of knowledge by pointing out the limitations of their current thinking. Furthermore, because each individual makes her or his own sense of knowledge, questions often do not have "right" answers. Questions are points of departure for each individual's development and construction of knowledge.

\section{Errors}

\section{Intensive-Explicit}

Within IE instruction, errors are viewed within the larger context of students' developing, mastering, and fluently using knowledge. That is, the IE instructional process is seen as a methodology for students to gain confidence and develop skills by pointing out errors and explaining how they can be eliminated. Teachers address errors in a routine that begins with authentic acknowledgement of students' achievement on practice attempts. Following this, one or two categories of error are identified, and the teacher explains and models for students how to overcome the error.

By progressively overcoming errors, and building fluency, students overcome learned helplessness and become independent learners. Therefore, learning how to overcome errors is an important way in which students develop during IE instruction. Pressley (in Pressley et al., 1992) comments that during "good strategy instruction ... errors are used not to penalize students, but rather as diagnostic tools, permitting the strategy teacher insights into the student processes" (p. 19-20).

\section{Constructivist}

Poplin comments that "probably the most significant and obvious difference between constructivist notions of learning and reductionist theories is the way in which error is perceived in the classroom" (Poplin, 1988a). In a constructivist classroom, errors are seen as the natural outgrowth of risk taking and meaningful learning. Mistakes are an essential component of the construction of knowledge; they are indicators that learning is taking place. "Constructivists ... seek to create environments where 'penalty-free' errors can emerge and be realized" (Poplin, 1988a). In this sense, errors are to be celebrated, and teachers should not attempt to correct students when they are trying to learn.

As Brooks and Brooks (1993) state, " 'No' hurts, and makes students feel invalidated and foolish. 'No' communicates to students that their idiosyncratic thinking about issues is not particularly valued. It erodes their desire to think about and explore issues" (p. 86). In addition, constructivists suggest that it is often naïve to assume that there is a "right answer." Heshusius (1995) states, "The wrong answer can be perfectly right where it is the result of a personal and often complex process the child goes through" ( $p$. 182).

\section{Activities}

\section{Intensive-Explicit}

During IE instruction, learning activities are set up so that students can become independent, empowered learners through activities that lead to mastery and fluent use of content. Students engage in a variety of activities. For example, they may watch or interact during teacher modeling of content, respond to questions, practice developing skills and strategies, listen to instructions or feedback, or apply new knowledge as they build their abilities. Assignments are 
structured so students can build their understanding of complex content through practice on increasingly difficult materials.

Students might work together or work independently. However they learn, the overriding goal is to learn the material that the teacher has presented. Students in an effective IE class are highly engaged, motivated by the progress they experience and by mastering knowledge.

\section{Constructivist}

Constructivist instruction involves students in activities that enable them to construct and reconstruct knowledge. Constructivist learning experiences may take many different forms. The Early Literacy Project (Englert et al., 1995) provides one example of how Vygotsky's social constructivism can be embodied in student activities. Students participating in the Early Literacy Project are engaged in "meaningful, purposeful, and integrated activities," and they take part in classroom dialogues that involve them "in social interactions within a cognitive apprenticeship model" (p. 254). Students experience "scaffolded instruction (word banks, partner reading) that ... [allows] ... them "to engage in reading and writing in advance of independent performance" ( $\mathrm{p}$. 261).

Students in a learning experience that is truly constructivist should find themselves swept up in activities that they find meaningful. In addition, they should progress and develop at the pace that is uniquely appropriate for them. Their learning experiences are interdisciplinary and not restricted by subject area. Thus, students may tackle complex problems that require knowledge from several disciplines.

\section{Motivation}

\section{Intensive-Explicit}

Student motivation in the intensive-explicit approach arises from a variety of factors. To begin with, in some approaches involvement is cast as a choice, with students being asked to make a personal commitment before instruction begins (Ellis et al., 1991). Teachers using IE are also explicit about the rationales for learning content and guide students to see the value in the learning they are experiencing through direct explanation in classroom conversation.

In addition, IE instruction is structured specifically to encourage student motivation, sharing many of the structural components of what others have identified as motivating or optimal experience (Csikszentmihalyi, 1991). That is, learning is set up so there is an ideal balance between the challenges of the activity and the skills of the student. Learning starts at an appropriate skill level for each student and then gets progressively more challenging as the children master content.

Also, while they are learning, students set goals and receive feedback on their progress toward their goals (Kline et al., 1991). Pressley (1992) comments, "Throughout instruction, teachers attempt to keep motivation high, largely by highlighting the empowerment that accompanies acquisition of powerful procedures that accomplish important academic tasks" (p. 11).

\section{Constructivist}

Students are motivated to learn during constructivist instruction because the learning they experience provokes their interest, inspires their curiosity, or is pleasurable. Students are motivated because they are curious to learn more about whatever problem they are considering. Students work on, explore, and play with material that is personally meaningful for them because "learners learn best from experiences about which they are passionately interested and involved" (Poplin, 1988a, p. 405).

Assignments also are "holistic activities" (Englert \& Marriage, 1996) that provide students with the context for understanding why they learn what they learn. Thus, students who are learning about literacy experience it in the broader context of communication to create a community of learners. Students may write in journals, share their writing with others, engage in dialogues about writing, have their writing displayed in the classroom, write for multiple audiences, write with partners and in groups, and so on (Graham et al., 2001).

During constructivist instruction, teachers pay particular attention to creating an environment that frees students to experience the inherent joy of learning. Constructivist instruction emphasizes the important role that community plays for students' developing knowledge. In addition, constructivists try to create a setting in which students feel free to learn, by reducing disincentives in the classroom. Thus, as noted, teachers using constructivist instruction deemphasize students' errors so students will trust their teachers and be willing to take risks (Poplin, 1988a).

\section{Truth and Reality}

\section{Intensive-Explicit}

As noted, the intensive-explicit approach to instruction is not the product of one ontology, and it is possible to support both constructivist and IE instructional practices (Harris \& Graham, 1996; Mercer, Jordan et al., 1996; Pressley et al., 1992). Nevertheless, a pedagogy intent on ensuring that students master the content chosen by teachers would seem to be most appealing to a teacher who believes there is an objective reality that everyone can reference and understand. 
Perhaps IE teachers take a practical approach, choosing to assume, for the moment at least, that we can know laws and facts and act on them with certainty. To be sure, when we are riding a commercial jet, it is more reassuring to assume that the pilot believes in an objective reality than to believe that the pilot has constructed his or her own unique understanding of piloting and now will fly the plane accordingly.

Some IE instructors are impatient with constructivist theorizing. As one teacher and graduate student commented, "You have to stay in school a long time and read a lot of philosophy before you can start to wonder if reality is real or not." An instructor taking the IE approach may be inclined to put brackets around theorizing, and focus instead on enabling students to master essential skills and strategies (such as the ability to read and communicate orally and in writing).

Intensive-explicit instruction takes the perspective that there are rules, laws, concepts, and terms that competent people know, and that one important task for a teacher is to ensure that students have acquired that knowledge. Thus, IE instruction positions the teacher as an expert teaching students who have varying degrees of expertise.

Because it assumes the existence of objective reality, intensive-explicit instruction also places particular emphasis on how the environment affects student behavior. Consequently, intensive-explicit instruction is more behaviorist in orientation, often employing progress charts, goal-directed behavior, and the use of extrinsic rewards to shape behavior (Deshler \& Schumaker, 1988).

\section{Constructivist}

From the constructivist perspective, the individual nature of constructivist epistemology renders objective reality a myth (Segal, 2001). "There is nothing 'out there' that is separate from our own construction of it. Reality is minddependent. In other words, we construct what we know. Who we are, with all our values, interests, and various needs, is part and parcel of what we come to construct as knowledge" (Heshusius, 1995, p. 175).

A constructivist epistemology leads to a different understanding of what a teacher's job is. Constructivists reject the idea that the teacher is the source of most knowledge in the classroom, and, indeed, they hold open to question all knowledge. Thus, the constructivist teacher's task is "to help students to search rather than follow" (Brooks \& Brooks, 1993, p. 102).

Constructivist and intensive-explicit approaches to instruction differ in many ways, including the teacher's role, the type of conversations and questions, the way errors are perceived, what students do, how they are motivated, and even how reality and truth are perceived are all points of contrast between these two approaches. Despite these differences, however, I believe that constructivist and intensive-explicit instruction can be used together to accommodate the weaknesses in each approach. For that reason, we will next consider points of convergence between intensive-explicit and constructivist instruction.

\section{POINTS OF CONVERGENCE}

Contrasting intensive-explicit and constructivist approaches has brought to light the significant differences between these two approaches. I believe that classrooms integrating both approaches might serve students better than classrooms adhering to one or the other of these approaches dogmatically. Each approach has limitations that are accommodated by each other's strengths. For that reason, we can better understand how constructivist and intensive-explicit instruction might be integrated more effectively by first reviewing the criticisms of each approach.

Looking at each instructional approach from the outside, so to speak, brings out possible limitations in both approaches, thereby suggesting points at which the two approaches might come together. Once we have considered the critiques of both approaches, we will offer some ways by which the two approaches might work together.

\section{Constructivist Critique of Intensive-Explicit Instruction}

From the unique perspective afforded by their paradigm, constructivists, have criticized IE instruction as being "reductionist." According to Poplin (1988b), "Reductionism is the natural process by which we break ideas, concepts, and skills into parts in an attempt to understand and deal better with the whole" (p. 394). Constructivists contend that this "bits and pieces" approach to education (Heshusius, 1995 , p. 178) removes the real meaning and pleasure from learning. Life is much more complex, ambiguous, and messy than learning that can be summarized on a learning sheet, and effective pedagogy should, therefore, recognize and privilege that ambiguity.

Another criticism leveled at intensive-explicit instruction is that it involves students in learning experiences divorced from real, meaningful life. For example, Heshusius rejects the teaching practices of "mastery of components ... the idea of additive and linear progress, and the view of the students as reactive (meaning active only in reaction to the teacher's curriculum ... [as being based] on outdated beliefs inherent in the mechanistic paradigm" (p. 171).

IE instruction is criticized as a model that leads teachers to spend the bulk of their time preparing students, leaving little time for meaningful learning experiences. To illustrate, 
Heshusius cites a student's comment, "When are we going to stop readin' reading and start reading something?" (p. 178).

Constructivists cite Friere's notion of banking education, that teachers do not enable students to experience meaningful dialogue, as a critique of IE instruction. Although IE is interactive, and although during IE instruction there can be meaningful dialogue about how, where, and why to generalize learning, there is little dialogue in the sense Friere proposes. Dialogue during IE instruction, then, is not a form of praxis - that is, an activity that involves authentic reflection and reconstruction of knowledge (Friere, 1997).

A final critique, offered most forcefully by Poplin (1988b), is that IE fails to properly enable students to generalize learning. Although IE often involves practice and feedback, as well as the teaching of prerequisite skills and strategies, constructivists contend that because this is learning in preparation for real tasks, as opposed to real experiences themselves, students fail to generalize IE learning.

\begin{abstract}
Learning a skill one day and forgetting it the next is often implied as a characteristic of the learning disabled student. I propose, however, that this characteristic is more a result of reductionistic methods we employ than a characteristic of the students we serve. (Poplin, 1988b, pp. 393-394)
\end{abstract}

\section{Intensive-Explicit Critique of Constructivism}

When viewed from the perspective afforded by the IE paradigm, or at least from vantage points that are not entirely constructivist, the constructivist approach to instruction is also seen as having limitations. The constructivist predilection to deemphasize the limitations of students with learning disabilities (Poplin, 1988b), for example, has been criticized for putting students into learning situations from which they are unable to benefit fully.

Researchers who adopt an IE perspective believe that students with learning disabilities are students who come to learning with challenges that make it difficult for them to complete certain tasks (for example, decoding or comprehending texts, writing, social discourse, or reasoning). A learning disability, by definition, denies learners access to learning experiences that other children experience fully. Rather than deemphasizing limitations, the IE perspective holds that a central goal of special education is to ensure that students with disabilities develop the strategies and skills they need to ultimately have barrier-free access to curriculum (Deshler et al., 2001).

A second criticism of constructivism is that by ignoring mistakes and celebrating risk taking, teachers may not adequately attend to the important goal of ensuring that students acquire foundational knowledge essential for independent performance (Cromer, 1997). Teachers who adopt a constructivist approach to teaching reading may provide students with stimulating learning activities that enable students to piece together their own understanding of reading, but from the IE perspective such an approach might leave students dangerously at-risk because it does not systematically teach students essential components such as phonemic awareness. For example, Stanovich (1994) comments:

\begin{abstract}
The idea that self-discovery is the most efficacious mode of learning, that most learning can be characterized as "natural," and that cognitive components should never be isolated or fractionated during the learning process have been useful as tenets for comprehension instruction, but are markedly at variance with what is now known about the best ways to develop word recognition skill. Research has indicated that explicit instruction and teacher-directed strategy training are more efficacious, and that this is especially true for at-risk children, children with learning disabilities, and for children with special needs. (p. 259)
\end{abstract}

\section{First Point of Convergence: \\ Mechanical versus Metaphorical Knowledge}

Both IE and constructivist instruction may address some of the limitations of each other. For example, as noted, IE instruction has been criticized for reducing rich learning experiences, whereas constructivism has been criticized for not ensuring that students master essential skills. Allowing students to discover how to read texts without IE instruction in some essential decoding skills might leave students unprepared for some academic tasks. At the same time, a step-by-step strategy to teach students how to determine the correct meaning of a story might significantly interfere with a student's meaningful appreciation of the story.

Appreciating a story seems to be an especially appropriate kind of activity for constructivist pedagogy. Wolfgang Iser has suggested that the act of reading a story is inherently constructivist, with readers identifying "gaps" in the text and constructing their own reading by filling in the gaps. In addition, readers create their own pictures of the setting, connect the narrative with their personal experiences, interpret the message of the story, if one exists, through the lens of their own morality, and so on.

In a very real sense, we all read our own story. Poplin comments that, for this reason, "Two adults reading the same novel often see the novel's message very differently because each person brings to the novel different experiences that interact in the text with significantly different ways" (Poplin, 1988a).

I refer to knowledge, such as that derived from reading a story, as metaphorical knowledge. It is by definition ambiguous, and functions indirectly. Metaphorical knowledge has no clearly right or wrong outcome. For example, each person determines and develops his or her own 
understanding of intellectual attributes such as aesthetic response, personal attributes such as compassion or heroism, and many creative acts such as higher-order writing activities. Metaphorical knowledge is complex, so ambiguous, and so uniquely individual that we damage it if we reduce it. For that reason, constructivist instruction may be more appropriate for metaphorical knowledge.

Not all knowledge to be learned is as complicated as our aesthetic response to narrative. When the content to be learned in a class is not ambiguous, and when the outcomes are unmistakable, perhaps an IE approach is more appropriate. For example, learning how to identify subjects and verbs in sentences (a skill that is necessary for meaningful conversation about many editorial concerns, such as run-on sentences, sentence fragments, subject-verb agreement, and verb tense) is fairly straightforward. Whether someone has or has not correctly identified the subject of a sentence is easily determined without ambiguity.

Knowledge that is unambiguous, when a right and wrong answer can be clearly identified, I have come to refer to as mechanical knowledge. Examples of mechanical knowledge are phonological awareness, some learning strategies, memorization of essential concepts terminology, and grammatical terms and concepts.

On the surface, IE instruction seems to be a superior pedagogy for enabling students to acquire mechanical knowledge because mechanical knowledge is unambiguous. When teachers can clearly identify a correct answer, they might find it more efficient to teach in a way that ensures that students share the same knowledge they do. IE instruction is a method for ensuring mastery of content, and for that reason it seems to be the most efficient and effective way to teach mechanical knowledge.

By the same token, constructivist instruction could be a superior pedagogy for metaphorical knowledge. If knowledge is so complicated and ambiguous that it cannot be reduced to a simple and clear explanation, perhaps the best way for students to make sense of it is through exploration, and dialogue, social construction in the classroom. When knowledge seems uniquely personal, such as how to define empathy or respect, perhaps a constructivist approach is more effective.

If students are failed by the education they receive today, perhaps that is because they experience the wrong pedagogy for the kind of knowledge they are learning. Perhaps, when students are taught five steps to understanding a poem, or are compelled to memorize the names of famous authors during literature classes, they lose sight of the emotional power and beauty of poetic expression.

In addition, when they are left on their own to discover how to construct a correct sentence, and not given intensive-explicit instruction on grammatically correct forms of expression, perhaps they are frustrated by what they do not know. By reducing the experience of literature, teachers can take the heart and soul out of it. Similarly, by leaving students free to construct their own sentences, without ensuring that they master some basic rules, teachers can frustrate students who are tentative and unsure of their abilities.

Mechanical knowledge is like the rules of a game that everyone must know before the game begins. Once the rules are mastered, however, the artistry of the game begins, and that is when metaphorical knowledge becomes more important.

\section{Second Point of Convergence: Tacit Knowledge}

Michael Polanyi's work represents an alternative way of considering constructivism that also represents a point of convergence between constructivist and IE instruction. Polanyi (1966) distinguished between the "tacit" and "explicit" aspects of knowledge. The tacit dimensions are those aspects of knowing that are so well internalized that we are unconscious of them. According to Polanyi, "We can know more than we can tell" (p. 4).

We can better understand tacit knowledge by considering an example. Imagine an outstanding hockey player. If we watch him or her play the game, we'll notice that the player performs with a level of expertise that is superior to others. Maybe the player seems to know just the right time to shoot the puck to score, the most efficient way to avoid opposing checkers, the best time to pass the puck to teammates, or the most appropriate place to skate to intercept a pass. An outstanding player seems to have an almost innate ability to see, act, and anticipate that enables outstanding performance. As the greatest hockey player of all time, Wayne Gretzky, has said, "I skate to where the puck is going to be."

If we were to interview such an outstanding player and ask him or her to explain how we could become similarly expert, chances are the player would not be able to tell us what he or she does to attain it. Expert performance is often something that is constructed and internalized over time. Polanyi called this process "indwelling." Once tacit knowledge becomes internalized, it can shape the way we think, move, and perceive, and often it is invisible to us. I would argue that there is a significant tacit dimension to the expertise of any skillful actor, whether we are talking about a hockey player, an airplane mechanic, a teacher, or a reader.

According to Polanyi, explicit knowledge stands in contrast to tacit knowledge. Explicit knowledge refers to knowledge that can be articulated in language and shared. Explicit knowledge, for example, is represented by grammar, mathematical formulas, and the specifications written in manuals. Explicit knowledge, because it has been encoded in language, can be shared. Explicit knowledge is the principal form of knowledge in schools today. 
If we return to our hockey player, we will see that explicit knowledge also plays an important role in the player's development. Not all learning occurs on the fly, in the midst of the game, and most skillful players learn a great deal from various forms of IE instruction that teach them explicit knowledge. For example, masterful players might have attended power skating sessions to develop speed and agility on skates, or learned a step-by-step procedure for how to pass or shoot in a variety of effective ways.

No doubt, if they received effective instruction from coaches, they heard explicit instructions, watched multiple models of expert performance, developed their skills through progressively more difficult practices, received constructive feedback that enabled them to master their skills, and then generalized their developing skills in real-game situations. Tacit knowledge may be the dimension of knowledge that is most important, but much tacit knowledge is constructed, in part, as a result of explicit instruction.

Our example suggests another way in which the interplay between constructivist and intensive-explicit instruction might be structured. Perhaps IE instruction is necessary for some forms of explicit knowledge, whereas constructivist pedagogy is necessary to enable the "indwelling" of knowledge. IE instruction, then, can be used to teach students the knowledge that is codified in language and easily communicated, but constructivist instruction can be used to help students transform explicit knowledge into the tacit dimension.

\section{Third Point of Convergence: Competence and Connoisseurship}

The potential for interplay between constructivist and intensive-explicit instruction is broadened by work in linguistics, literary criticism (Culler, 1975) and aesthetic response (Eisner, 1991). All of these writers posit ways in which tacit knowledge enables us to masterfully interact with the world.

Eisner (1991) agrees with Polanyi that tacit knowledge plays a significant role in how we experience and appreciate the world. "Perception," he says, "is a function of the transactions between the qualities of the environment and what we bring to those qualities" (p. 63). Eisner explores this phenomenon by discussing connoisseurship. According to Eisner, a person develops the abilities of a connoisseur by internalizing knowledge that enables the masterful perception of some object.

To illustrate his idea, Eisner uses the example of a wine connoisseur. A wine connoisseur's expertise has to enable him or her to perceive and differentiate taste, color, and scent. The connoisseur has to place wine in its appropriate class, understand the science of winemaking, and bring other components of "antecedent knowledge" into play so as to fully appreciate a wine. Eisner extends the concept of connoisseurship to life in general:

\begin{abstract}
To some degree all people have some degree of connoisseurship in some area of life. In virtually all cases, however, the level of their connoisseurship can be raised through tuition. Teachers of literature can help people learn how to read a novel. . . . Coaches help players learn how to read.a field of play in motion. ... Critics of film and painting help others learn to see what they might otherwise not notice. In the process, people's consciousness is raised, and they become more able to notice and respond to such material. (p. 69)
\end{abstract}

Culler (1975) makes similar claims about the role of knowledge in appreciating experience in his description of "literary competence." Drawing on Noam Chomsky's notion of linguistic competence, like Eisner, Culler sees our experience of the world as a being shaped by what we bring to experience. He summarizes Chomsky's notion of linguistic competence, an explanation of how our understanding of language is predicated upon a complex web of tacit and explicit knowledge, as follows:

\begin{abstract}
Whenever a speaker of a language hears a phonetic sequence, he is able to give it meaning because he brings to the act of communication an amazing repertoire of conscious and unconscious knowledge. Mastery of the phonological, syntactic and semantic systems of his language enables him to convert the sounds into discrete units, to recognize words, and to assign a structural description and interpretation to the resulting sentence, even though it be quite new to him. Without this implicit knowledge, this internalized grammar, the sequence of sounds does not speak to him. (p. 113)
\end{abstract}

Culler extends the idea of competence to include the appreciation of literature and, like Eisner, concludes that the ability to sense a work in all of its richness requires extensive tacit knowledge. Just as we need linguistic competence to understand a speaker of a language, so we need "literary competence" to appreciate literary works.

To read a text as literature is not to make one's mind a $t a b$ ula rasa and approach it without preconceptions; one must bring to it an implicit understanding of the operations of literary discourse which tells one what to look for.... Anyone lacking this knowledge ... would be unable to read it as literature ... because he lacks the complex 'literary competence' which enables others to proceed. He has not internalized the 'grammar' of literature, which would permit him to convert linguistic sequences into literary structures and meanings. (p. 114-115)

By describing how tacit knowledge enables learning, Culler and Eisner provide a final point for considering how constructivist and IE instruction can be integrated. Perhaps IE instruction is necessary for clear and efficient teaching of skills, strategies, conceptual knowledge, and so on, which are necessary components of being a connoisseur or of 
being competent in a discipline in the way Culler defines competence. Our rich construction of experience can be enhanced through intensive-explicit instruction.

\section{CONCLUSION}

In recent years, several authors have reconsidered the contention that constructivist and intensive-explicit instruction are mutually exclusive pedagogies (Harris \& Graham, 1994; Pressley et al., 1992). I believe we will all benefit if this integrative exploration continues to be an important part of the conversation taking place in the research literature and in schools.

I have offered additional conversation starters and points to ponder by comparing and contrasting constructivist and intensive-explicit instruction and suggesting ways in which the two approaches may be integrated. Perhaps the strengths of each approach can accommodate the limitations of each. For example, if intensive-explicit learning takes place within the authentic, holistic learning experiences proposed by constructivist instruction, students will be more likely to generalize and internalize their learning. In the same light, if IE instruction is used to teach essential communication, literacy, computational, and social skills and strategies to students who are experiencing constructivist instruction, perhaps students will be better prepared to participate in activities that call for social construction of knowledge.

More research can help educators better understand how the two approaches can be integrated. My conception of mechanical and metaphorical knowledge may be one starting point. Although both mechanical and metaphorical knowledge exist along a continuum, the suggestion that intensive-explicit instruction is more appropriate for mechanical knowledge and that constructivist instruction is more appropriate for metaphorical knowledge appears to have face validity.

Polanyi's work provides another way of thinking about how to bring together the two approaches. Specifically, the distinction Polanyi makes between explicit and tacit knowledge provides a framework for better understanding how constructivist and intensive-explicit instruction can be integrated. The goal of internalization or generalization, central to both instructional approaches, may be better understood as the transformation of explicit knowledge into tacit knowledge, the act Polanyi refers to as "indwelling."

Finally, Culler's "competence" is a possible model for bridging the gap between constructivist and intensiveexplicit instruction, as is Eisner's "connoisseurship." Chomsky's linguistic competence can be extended, as Culler suggests, to include literary competence and, I submit, scientific competence, mathematical competence, historical competence, as well as competence in many other disciplines. Therefore, if our experience of a phenomenon is dependent upon the development of "competence" through internalization of extensive tacit and explicit knowledge, educators need to consider carefully what kind of knowledge enables competence in each discipline. We need to better understand when IE instruction and constructivist instruction are most appropriate for teaching prior knowledge for these competencies, competencies that will enable people to construct richer, more meaningful experiences in life.

\section{FINAL THOUGHTS}

This article began with the story of Alex, who was diagnosed as having a learning disability but who learned a complicated video game so quickly that he mastered it in 4 days. The two instructional approaches considered here suggest different reasons that Alex learned his video game so well.

A constructivist might suggest that Alex was successful because he was working on an authentic task that was meaningful to him, that he felt free to make errors, that the game provided him a chance to internalize learning in a realworld, (if a video game can be considered real world) experience. Alex was not learning prerequisite skills for video games; he was learning while playing the game.

A teacher using intensive-explicit instruction might see Alex's success from a different perspective. Perhaps Alex learned the game quickly because his learning was goal-oriented, and his practice attempts were structured with increasing difficulty so he was able to master skills and keep moving forward to more complicated levels of the game. Maybe Alex was successful because he received immediate feedback on his correct and incorrect moves, and thus learned to eliminate errors and play the game with mastery.

Looking at Alex's learning from these different vantage points provides us with a much broader picture of the boy's learning experience. In brief, we have the potential to see more because we see from two different perspectives.

I hope that this discussion illustrates how better understanding constructivist and intensive-explicit instruction holds the potential to help us see more. By continuing to look at constructivist and intensive-explicit instruction from each other's vantage point, and by looking for innovative and powerful ways to integrate these two approaches, I hope we will learn how to render education more effective, authentic, and enjoyable for all children. Perhaps by learning how to better blend constructivist and intensive-explicit instruction, we can learn how to better create learning experiences that children find as captivating as Alex did his video game. 


\section{REFERENCES}

Bandura, A. (1971). Social learning theory. New York: General Learning Press.

Bernstein, R. J. (1991). Beyond objectivism and relativism. Philadelphia: University or Pennsylvania Press.

Bohm, D. (1996). On dialogue. New York: Routledge.

Borkowski, J., \& Muthukrishna, N. (1992). Moving metacognition into the classroom: "Working models" and effective strategy teaching. In E. McIntyre \& M. Pressley (Eds.), Balanced instruction: Strategies and skills in whole language. Norwood, MA: Christopher-Gordon.

Brooks, J. G., \& Brooks, M. G. (1993). In search of understanding: The case for constructivist classrooms. Alexandria, VA: Association for Supervision and Curriculum Development.

Cromer, A. (1997). Connected knowledge: Science, philosophy, and education. New York: Oxford University Press.

Csikszentmihalyi, M. (1991). Flow: The psychology of optimal experience. New York: HarperCollins.

Culler, J. (1975). Structuralist poetics: Structuralism, linguistics and the study of literature. London: Routledge \& Kegan Paul.

Deshler, D., \& Schumaker, J. B. (1988). An instructional model for teaching students how to learn. In J. L. Graden, J. E. Zins \& M. J. Curtis (Eds.), Alternative educational delivery systems: Enhancing instructional options for all students. (pp. 391-411). Washington, DC: National Association of School Psychologists.

Deshler, D. D., \& Schumaker, J. B. (1993). Strategy mastery by at-risk students is not a simple matter. The Elementary School Journal, 94, 153-167.

Deshler, D., Shumaker, J., Bulgren, J., Lenz, K., Jantzen, J.-E., \& Adams, G., et al. (2001). Making learning easier: Connecting new knowledge to things students already know. Teaching Exceptional Children, 33(4), $82-85$.

Deshler, D. D., Schumaker, J. B., Lenz, B. K., Bulgren, J. A., Hock, M. F., Knight, J., et al. (2001). Ensuring content-area learning by secondary students with learning disabilities. Learning Disabilities Research and Practice, 16(2), 96-108.

Eisner, E. W. (1991). The enlightened eye: Qualitative inquiry and the enhancement of educational practice. New York: Macmillan.

Ellis, E., Deshler, D. D., Lenz, B. K., Schumaker, J. B., \& Clark, F. L. (1991). An instructional model for teaching learning strategies. Focus on Exceptional Children, 23(6), 1-24.

Englert, C. S., Garmon, A., Mariage, T., Rozendal, M., Tarrant, K., \& Urba, J. (1995). The early literacy project: Connecting across the literacy curriculum. Learning Disability Quarterly, 18(4), 253-275.

Englert, C. S., \& Marriage, T. V. (1996). A sociocultural perspective: Teaching ways-of-thinking and ways-of-talking in a literary community. Learning Disabilities Research and Practice, 11(3), 157-167.

Friere, P. (1997). Pedagogy of the oppressed (M. B. Ramos, Trans. 20th-Anniversary ed.). New York: Continuum.

Gildroy, P. (2001). The development and evaluation of an instructional modeling routine for students with learning disabilities. Unpublished doctoral dissertation, University of Kansas: Kansas.

Glasersfeld, E. V. (1995). Radical constructivism. Washington, DC: Falmer Press.

Graham, S., Harris, K., \& Larsen, L. (2001). Prevention and intervention of writing difficulties for students with learning disabilities. Learning Disabilities Research and Practice, 16(2), 74-84.

Harris, K., \& Graham, S. R. (1994). Constructivism: Principles, paradigms, and integration. Journal of Special Education, 28(3), 233-247.

Harris, K., \& Graham, S. (1996). Constructivism and students with special needs: Issues in the classroom. Learning Disabilities Research and Practice, 11(3), 134-137.
Harris, K., \& Graham, S. (1999). Programmatic intervention research: Illustrations from the evolution of self-regulated strategy development. Learning Disability Quarterly, 22(Fall, 1999), 251-262.

Heshusius, L. (1995). Holism and special education: There is no substitute for real life purposes and processes. In T. M. Skrtic (Ed.), Disability and democracy: Reconstructing (special) education for postmodernity (pp. 166-189). New York: Columbia University, Teachers College.

Iser, W. (1978). The act of reading: A theory of aesthetic response. Baltimore: The Johns Hopkins University Press.

Kline, F. M., Schumaker, J. B., \& Deshler, D. D. (1991). The development and validation of feedback routines for instructing students with learning disabilities. LD Forum, 14, 191-207.

Kuhn, T. (1970). The structure of scientific revolutions (2d ed.). Chicago: University of Chicago Press.

Mariage, T. V. (2000). Constructing educational possibilities: A sociolinguistic examination of meaning-making in "sharing chair." Learning Disability Quarterly, 23(Spring 2000), 79-103.

Meichebaum, D. M. (1977). Cognitive behavior modification. New York: Plenum.

Mercer, C. D., Jordan, L., \& Miller, S. P. (1996). Constructivistic math instruction for diverse learners. Learning Disabilities Research and Practice, 11(3), 147-156.

Mercer, C. D., Lane, H. B., Jordan, L., Allsop, D. H., \& Eisele, M. R. (1996). Empowering teachers and students with instructional choices in inclusive settings. Remedial and Special Education, 17(4), 226-236.

Mok, C. (2003, January). Idea fest. Fast Company, p. 103.

Moll, L. C. (1990). Introduction. In L. C. Moll (Ed.), Vygotsky and education: Instructional implications and applications of sociohistorical psychology. Cambridge, UK: Cambridge University Press.

Moshman, D. (1982). Exogenous, endogenous, and dialectical constructivism. Developmental Review, 2, 371-384.

Phillips, D. C. (2000). An opinionated account of the constructivist landscape. In D. C. Phillips (Ed.), Constructivism in education (pp. 1-16). Chicago: National Society for the Study of Education/University of Chicago Press.

Piaget, J. (1954). The construction of reality in the child. New York: Ballantine Books, Inc.

Polanyi, M. (1966). The tacit dimension. London: Routledge \& Kegan Paul.

Poplin, M. S. (1988a). Holistic/constructivist principles of the teaching/ learning process: Implications for the field of learning disabilities. Journal of Learning Disabilities, 21(7), 401-416.

Poplin, M. S. (1988b). The reductionist fallacy in learning disabilities: Replicating the past by reducing the present. Journal of Learning Disabilities, 21(7), 389-400.

Poplin, M. S. (1995). Looking through other lenses and listening to other voices: Stretching the boundaries of learning disabilities. Journal of Learning Disabilities, 28, 392-398.

Pressley, M., Burkell, J., Cariglia-Bull, T., Lysynchuk, L., McGoldrick, J. A., Schneider, B., et al. (1990). Cognitive strategy instruction that really improves children's academic performance. Cambridge, MA: Brookline Books.

Pressley, M., Harris, K., \& Marks, M. B. (1992). But good strategy instructors are constructivists! Educational Psychology Review, 4, 3-31.

Pressley, M., Hogan, K., Wharton-McDonald, R., Mistretta, J., \& Ettenberger, S. (1996). The challenges of instructional scaffolding: The challenges of instruction that support student thinking. Learning Disabilities Research and Practice, 11(3), 138-146.

Reid, D. K., Robinson, S. J., \& Bunsen, T. D. (1995). Empiricism and beyond: Expanding the boundaries of special education. Remedial and Special Education, 16(3), 131-141.

Roehler, L. R., \& Duffy, G. G. (1984). Direct explanation of comprehension processes. In G. G. Duffy, L. R. Roehler, \& J. Mason (Eds.), 


\title{
Curriculum Planning and Instructional Design for Gifted Learners
}

\author{
Joyce VanTassel-Baska
}

This comprehensive text establishes an exciting curriculum design model that caters to the unique needs of the gifted learner. While giving careful consideration to the current climate of educational reform, the text is able to preserve and enhance the important enterprise of gifted education.

The author's extensive experience in the field of gifted education makes this text an invaluable resource for students and teachers alike. Impressive in scope, the text gives thorough attention to crucial issues such as effective curriculum delivery, implementation strategies, and learner-outcome assessment.

Curriculum goals, learner outcomes, teacher-learning activities, instructional strategy design and selection, and management activities are among the important topics addressed in the individual chapters. The latter part of the book contains specific helpful sample curriculum units that exemplify strategies described throughout the book.

\section{SPECIAL FEATURES}

- Provides a comprehensive framework for curriculum planning.

- Designs an effective planning model for instruction.

- Outlines specific instructional strategies and curriculum units.

- Presents guidelines for learning assessment and curriculum evaluation.

\section{CONTENTS}

1 Introduction

2. Research on Curriculum Models in Gifted Education

3. Standards of Learning and Gifted Documents

4. Developing System-Wide Curriculum Documents

5. The Nature and Curriculum Needs of Gifted Learners

6. Developing a Philosophy and Goals for a Gifted Program

7. Developing Learner Outcomes

8. Designing Activities and Selecting Resources

9. Selecting Instructional Strategies

10. Employing Appropriate Curriculum Management Strategies

11. Implementing Curricula for the Gifted

12. Assessment of Learning and Evaluation of Curriculum

13. Toward Coherent Curriculum Policy in Gifted Education Appendix: Sample Curriculum Units 
Comprehension instruction: Perspectives and suggestions (pp. 265-280). New York: Longman.

Schumaker, J. B., Denton, P. H., \& Deshler, D. D. (1984). The paraphrasing strategy. Lawrence: University of Kansas.

Schwandt, T. A. (1994). Constructivist, interpretive approaches to human inquiry. In Denzin \& Lincoln, 1994, pp. 118-137.

Segal, L. (2001). The dream of reality: Heinz von Foerster's constructivism (2d ed.). New York: Springer.

Seligman, M. E. P. (1992). Helplessness: On development, depression, and death. New York: W. H. Freeman and Co.
Skrtic, T. M., Sailor, W., \& Gee, K. (1996). Voice, collaboration and inclusion: Democratic themes in educational and social reform initiatives. Remedial and Special Education, 17(3), 142-157.

Stanovich, K. E. (1994). Constructivism in reading. Journal of Special Education, 28(3), 259-274.

Vygotsky, L. S. (1978). Mind in society (M. Cole, V. John-Steiner, S. Scribner \& E. Souberman, Trans.). Cambridge, MA: Harvard University Press.

Wood, D., Bruner, J., \& Ross, G. (1976). The role of tutoring in problem solving. Journal of Child Psychology and Psychiatry, 17, 89-100.

\section{Council for Exceptional Children}

April 9-12, 2003

Seattle, Washington

Contact: $1-888-232-7733$ www.cec.sped.org
4156 Library Road

Pittsburgh, PA 15234 